\title{
Suicidal patients - the effect on staff
}

\author{
J. C. Rossiter, Senior Registrar, Tone Vale Hospital, Norton Fitzwarren, near Taunton, \\ Somerset
}

Although psychiatric hospitals contain a population at risk of suicidal behaviour compared to the community at large, suicide in hospital in-patients and recently discharged patients is relatively rare. It has been suggested that hospital admission itself reduces the risk of suicide (Tenroche et al, 1984). Factors considered important are a calm ward routine carried out by staff confident in the immediate future, and the opportunities for social contract offered by the ward environment.

At the same time there are a number of published reports from hospitals apparently afflicted by an "epidemic" of suicides (Langley \& Bayatti, 1984; Salmons, 1984). Some of these can be explained by situational factors in the hospital itself, for example psychiatric wards on the top floors of tall buildings, but other cases are less easily understood. This study reports the attitudes of nursing staff in a hospital where ten patients had died (nine recorded as suicide, one as accidental death) either in hospital or within a week of discharge in a 14 month period.

\section{The study}

The hospital

The hospital is an 'old style' psychiatric hospital. It has about 350 in-patients comprising acute, longstay, psychogeriatric and rehabilitation patients.

\section{The patients}

The patients comprised eight men and two women, and their ages ranged from 28 years to 84 years. Six were diagnosed as suffering from depressive disorder and four from schizophrenia. Eight patients had had previous admissions to hospital. The two patients on their first admissions had been in hospital a relatively long time, over five months in one case and 34 years in the other. Four patients committed suicide within a week of discharge and six died while in-patients.

\section{The stafi}

The staff interviewed were the two most senior nurses who were permanent members on the ward on which the patient had been nursed prior to his death. These nurses were selected because of their seniority and their role as organisers of nursing policy towards patients.

\section{The questions}

Questions were asked to gain information in a number of areas concerning how the nurses had viewed the future for their patients. Questions were in the form of a semi structured interview. All interviews were held in private between two weeks and 12 months after the death of the patient known to the nurse - see Appendix.

\section{Findings}

Twenty nurses were interviewed. Sixteen of the 20 said that they considered their patient to have a 'chronic' illness and 19 of the 20 said that their patient would have been likely to require psychiatric treatment again in the future. Seven nurses considered that their patient's long-term prognosis was good. Nine nurses said that they felt that everything possible had been done for their patient. Twelve said that they felt that the patients' suicide was inevitable at some stage.

\section{Comment}

In many hospitals following such a death, some sort of review meeting may be held with all involved staff and sometimes also the other patients on the ward. The purposes of the review can include establishing the facts, determining what more could have been done, and allowing staff to ventilate their feelings.

As most untoward deaths of hospital patients result in an inquest, some staff may also have to prepare reports for the unit manager and be available to answer questions in the coroner's court. These procedures may have a tendency to make staff involved take up a defensive position.

The staff interviewed for this paper all recalled their patient clearly. All staff approached agreed to be interviewed and many seemed to welcome the chance to talk. Many spontaneously said that they would have liked more opportunity to discuss their feelings at the time. The results indicate that many of these nurses expressed pessimistic views about their patient's future.

It may be that these nurses had felt pessimistic about their patient's future throughout the admission or it may be that these attitudes are the nurses' way of coping with the loss of a patient. If it is 
the former then it could be speculated that the perceived lack of hope for his future in his carers may have had an effect on the distressed patient. Morgan (1981) has stressed the suicidal patient's ambivalence about life and death and the importance of staff in kindling hope rather than giving permission to die. If the latter is true, it is clear that for at least some nurses the myth has been established that there are some patients who 'cannot be helped'. Such myths can be perpetuated by reviews that conclude that everything possible had been done. The death of a patient by his own hand is a distressing event for all the professionals involved. Clearly it is not helpful or fair to attempt to apportion blame, but at the same time there may be useful lessons to be learnt from such a tragic event. We are still a long way from understanding the complex behaviour of suicide. Many factors are involved, mental illness being just one of them. It may be that the way such patients are handled by staff is important. It is recognised that the interaction between staff and patients can influence a patient's perspective on a problem (Rosenthal, 1976).

There is some evidence that suicide among psychiatric patients is increasing (Hesso, 1977). This may therefore be a good time to reassess how such events are handled as it is clearly important to give sensitive support to staff, but at the same time not to lose the chance of learning from the tragedy.

\section{References}

Hesso, R. (1977) Suicide in Norwegian, Finnish and Swedish psychiatric hospitals. Archiv für psychiatrie und nervenkrankheiten, 224, 119-127.

LANGLEY, G. E. \& BAYATTI, N. N. (1984) Suicides in Exe Vale Hospital, 1972-1981. British Journal of Psychiatry, 145, 463-467.

MORGAN, H. G. (1981) Management of suicidal behaviour. British Journal of Psychiatry, 138, 257-260.

ROSENTHAL, R. (1976) Experimenter Effects on Behavioural Research. Howard University. New York: Irvington Publishers.

Salmons, P. H. (1984) Suicide in high buildings. British Journal of Psychiatry, 145, 469-472.

TenRoch, E., PUgh, T. F. \& MaCmahon, B. (1984) Suicide rates amongst current and former mental institution patients. Journal of Nervous and Mental Diseases, 138, 124-130.

\section{Appendix}

(1) Do you think that this patient was a chronic patient?

(2) Do you think that this patient would have required psychiatric treatment again in the future?

(3) Do you think that this patient's long-term prognosis was good?

(4) Could any more have been done for this patient?

(5) Would it have made a difference to the long-term outcome?

\title{
Privatisation of psychiatric care in the USA
}

\author{
Mohan P. Das, Diplomate of the American Board of Psychiatry and Neurology and \\ Associate Medical Director, Mental Health/Mental Retardation Center of East Texas, \\ Texas 75712, USA
}

Privatisation of psychiatric care is an increasing phenomenon in the USA. This is a relatively new trend and has followed on the heels of other trends like the deinstitutionalisation of the 1960 s and 70 s.
Until recently the majority of in-patient population was in public hospitals, with some in psychiatric units of general hospitals. In the 1980 s, the private hospital corporations seem to have discovered that there is 